\title{
CUTTING FORCES AND POWER DURING ELASTIC ABRASIVE CUTTING OF ROTATING WORKPIECES
}

\author{
Irina Aleksandrova, Gancho Ganev, Hristo Hristov
}

Original scientific paper

This paper presents the study and modelling of the complex impact of elastic abrasive cutting conditions: the force compressing the cut-off wheel to the workpiece, workpiece rotational frequency and cut-off wheel diameter on the forces and power of cutting when machining rotating steel workpieces. A generalized model for determining the specific cutting force has been created and on its basis empirical relationships for the tangential force and cutting power have been derived. The ratio between the tangential and normal forces has been analyzed as an evaluation parameter of the abrasive cutting process effectiveness.

Keywords: cutting forces; cutting power; elastic abrasive cutting; specific cutting force

\section{Sile i snaga rezanja tijekom elastičnog abrazivnog rezanja rotirajućih obradaka}

Izvorni znanstveni članak

U radu se daje analiza i modeliranje složenog djelovanja uvjeta kod elastičnog abrazivnog rezanja brusom: sile koja pritišće reznu površinu brusa uz obradak, rotacijske frekvencije obratka i promjera rezne površine brusa na sile i snagu rezanja kod obrade rotirajućih čeličnih obradaka. Stvoren je model za određivanje specifične sile rezanja i na temelju njega izvedeni su empirijski odnosi za tangencijalnu silu i silu rezanja. Odnos između tangencijalnih i normalnih sila analiziran je kao parameter za procjenu učinkovitosti abrazivnog reznog postupka.

Ključne riječi: elastično abrasivno rezanje; sile rezanja; snaga rezanja; specifična sila rezanja

\section{Introduction}

Abrasive cutting is a highly productive and economical method of machining workpieces of rods with a diameter of up to $60 \div 70 \mathrm{~mm}$ with cut-off wheels with a diameter of up to $400 \mathrm{~mm}$ and cut-out width of up to $4 \mathrm{~mm}$. The process is realized by different kinematical schemes $[1 \div 5]$, whereat the cut-off wheel performs the principal rotational and the radial feeding motion towards a stationary or rotating workpiece. After analysing the advantages and disadvantages of these schemes, a scheme of elastic abrasive cutting has been proposed which ensures constant area of the instantaneous cross-section of the material layer being cut by maintaining a constant force $F$ of compressing the cut-off wheel to a rotating workpiece (Fig. 1) [1].

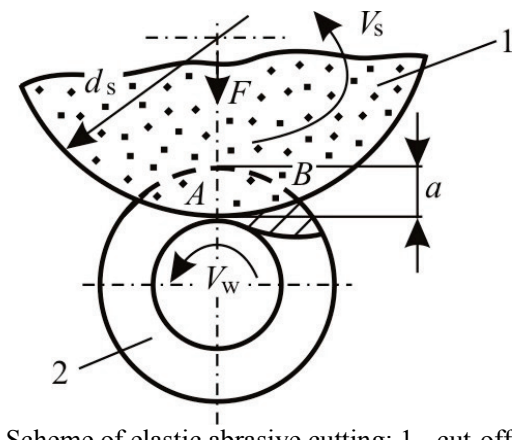

Figure 1 Scheme of elastic abrasive cutting: 1 - cut-off wheel; 2 workpiece

Normal cutting force $F_{\mathrm{p}}$ and tangential cutting force $F_{\mathrm{c}}$ act upon the abrasive tool. Normal force $F_{\mathrm{p}}$, tending to repulse the cut-off wheel from the workpiece, is equal to compressing force $F$. On the basis of experimental studies carried out in advance, it has been found that normal force $F_{\mathrm{p}}$ is greater than tangential force $F_{\mathrm{c}}$, which is a result of the hampered cutting-in of abrasive grains into the workpiece due to their irregular shape and adverse geometry as well as due to the small thickness of the layer being cut. The $F_{\mathrm{c}}$ vs. $F_{\mathrm{p}}$ forces ratio depends on abrasive cutting conditions [1].

During elastic abrasive cutting $F_{\mathrm{p}}=F$, and the magnitude of force $F_{\mathrm{c}}$, which determines cutting power $P_{\mathrm{c}}$, depends on specific cutting force $k_{\mathrm{c}}$ and instantaneous cross-section of the layer being cut. Various authors [6 $\div 14]$ for abrasive machining cite values of $k_{\mathrm{c}}$ within the range of $5000 \div 30000 \mathrm{daN} / \mathrm{mm}^{2}$, and these large values are explained by the very small thicknesses and crosssections of the layers being cut by the abrasive grains of the cut-off wheel as well as by the negative rakes of the grains. It has been established theoretically that the thickness and area of the instantaneous cross-section of the layer being cut during elastic abrasive cutting depend on the conditions for process realization: force of compressing the cut-off wheel to the workpiece, workpiece rotational frequency, cut-off wheel diameter and characteristic. All this requires a thorough study of the dynamic parameters of the elastic abrasive cutting of rotating workpieces.

The objective of this paper is to present the study and modelling of the effect of the conditions of elastic abrasive cutting of rotating steel workpieces on the tangential force and cutting power and obtaining relationships for determining the specific cutting force.

\section{Study of the dynamic parameters of the elastic abrasive cutting process}

2.1 Experimental study of the tangential force and cutting power

\subsubsection{Equipment, materials and methods}

The purpose of the experiment is to establish the correlation between the dynamic parameters of the elastic abrasive cutting process (cutting power $P_{\mathrm{c}}$ and tangential 
force $F_{\mathrm{c}}$ ) and the operating conditions for process realization. With regard to this, compressing force $F$, workpiece rotational frequency $n_{\mathrm{w}}$ and cut-off wheel diameter $d_{\mathrm{s}}$ have been chosen as controllable factors.

The experimental studies have been conducted during counter-directional cutting with cut-off wheels 41$180 \times 22.2 \times 3.0$ A30RBF. The machined material is $\mathrm{C} 45$ steel and it is in the shape of cylindrical rods with a diameter of $d_{\mathrm{w}}=30 \mathrm{~mm}$.

For the realization of the elastic abrasive cutting process, a special attachment has been designed [1], fixed on the main carriage of a combination lathe. The attachment comprises an angle-grinder which ensures constant rotational frequency of the cut-off wheel $\left(n_{\mathrm{s}}=\right.$ $8500 \mathrm{~min}^{-1}$ ), and a unit for regulating the magnitude of cut-off wheel compressing force $F$ to the workpiece. Workpiece rotational frequency $n_{\mathrm{w}}$ is set by a stepless adjustment device.

Cutting power $P_{\mathrm{c}}$ in $\mathrm{kW}$ is measured with a wattmeter and it is determined as the difference between the power consumed during cutting and the power of idle running.

To determine tangential force $F_{\mathrm{c}}$, the dependency expressing the relation between cutting power $P_{\mathrm{c}}$ and force $F_{\mathrm{c}}$ is used:

$F_{\mathrm{c}}=\frac{10^{3} P_{\mathrm{c}} \eta}{V_{\mathrm{s}}}=1,835 \times 10^{6} \frac{P_{\mathrm{c}}}{d_{\mathrm{s}} n_{\mathrm{s}}}, \mathrm{daN}$

where: $V_{\mathrm{s}}=\frac{10^{-3} \pi d_{\mathrm{s}} n_{\mathrm{s}}}{60}, \mathrm{~m} / \mathrm{s}$, is the speed of the principal rotational motion of the cut-off wheel; $n_{\mathrm{s}}$ is the cut-off wheel rotational frequency; $\eta$ is the efficiency coefficient.

The general form of the models describing the relationship between the studied parameters and the group of independent variables - the controllable factors: $d_{\mathrm{s}}\left(x_{1}\right)$, $F\left(x_{2}\right)$ and $n_{\mathrm{w}}\left(x_{3}\right)$, is:

$y_{g}=b_{0}+\sum_{i=1}^{3} b_{\mathrm{i}} x_{\mathrm{i}}+\sum \sum_{i<j} b_{\mathrm{ij}} x_{\mathrm{i}} x_{\mathrm{j}}$

where: $g=1,2 ; y_{1}=P_{\mathrm{c}}$ and $y_{2}=F_{\mathrm{c}}$.

The type of model has been chosen on the basis of analysis of controllable factors impact on the thickness and area of the instantaneous cross-section of the layer being cut which determine the tangential force and power during abrasive cutting.

To build the theoretical-experimental model (2) of cutting power, a multi-factor planned experiment is carried out. It is of the type $N=2^{k}$ ( $N$ is the number of experiments; $k=3$ is the number of controllable factors), and three observations are made for each experiment. The model is synthesized by actually measured values of cutting power. The variation limits of controllable factors are presented in Tab. 1. They are determined on the basis of preliminarily conducted studies of the serviceability of abrasive cut-off wheels evaluated by the parameters: tool wear and time per cut $[1,15,16,17]$.

The statistical analysis of experimental results is made in accordance with the methodology presented in [18], and it comprises a variance uniformity check of each experiment by Cochran criterion, error identification in the experiment, determination of coefficients in regression model in coded form, checking the regression coefficients significance by Student criterion, model adequacy check by Fisher criterion, controllable factors transfer from coded to decoded form in accordance with the relationships presented in Tab. 1.

Table 1 Controllable factors

\begin{tabular}{|c|c|c|c|}
\hline \multicolumn{2}{|c|}{ Factors } & \multirow[b]{2}{*}{$\begin{array}{l}\text { Basic level } \\
\tilde{x}_{\mathrm{i}, 0}\end{array}$} & \multirow[b]{2}{*}{$\begin{array}{c}\text { Variation } \\
\text { interval } \\
\lambda_{\mathrm{i}}\end{array}$} \\
\hline $\begin{array}{l}\text { natural } \\
\tilde{x}_{\mathrm{i}}\end{array}$ & $x_{\mathrm{i}}=\frac{\tilde{x}_{\mathrm{i}}-\tilde{x}_{\mathrm{i}, 0}}{\lambda_{\mathrm{i}}}$ & & \\
\hline$d_{\mathrm{s}}\left({ }^{\tilde{x}_{1}}\right) / \mathrm{mm}$ & $x_{1}=\frac{d_{\mathrm{s}}-150}{30}$ & 150 & 30 \\
\hline$F\left({ }^{\tilde{x}_{2}}\right) / \mathrm{daN}$ & $x_{2}=\frac{F-2}{1}$ & 2 & 1 \\
\hline$n_{\mathrm{w}}\left(\tilde{x}_{3}\right) / \min ^{-1}$ & $x_{3}=\frac{n_{\mathrm{w}}-39,5}{23,5}$ & 39,5 & 23,5 \\
\hline
\end{tabular}

The theoretical-experimental model (2) of the tangential cutting force is built on the basis of the model of cutting power and relationship (1), taking into account the relation between force $F_{\mathrm{c}}$ and cutting power $P_{\mathrm{c}}$.

\subsubsection{Experimental results}

After processing the experimental results concerning power during elastic abrasive cutting, the following adequate theoretical-experimental model is obtained: $\left(\hat{F}_{\mathrm{R}}=0,7556<F_{\mathrm{T}}=3,329 ; \hat{F}_{\mathrm{R}}, F_{\mathrm{T}}\right.$ are empirical and theoretical values of Fisher criterion; significance level $\alpha$ $=0,05)$ in coded form:

$$
\begin{aligned}
y_{1} & =1,8978+0,119 x_{1}+0,0815 x_{2}-0,127 x_{3}+ \\
& +0,0187 x_{1} x_{2}-0,0147 x_{1} x_{3}
\end{aligned}
$$

and in natural form:

$$
\begin{aligned}
P_{\mathrm{c}} & =0,417+3,54 \times 10^{-3} d_{\mathrm{s}}-0,012 F-2,28 \times 10^{-3} n_{\mathrm{w}}+ \\
& +6,23 \times 10^{-4} d_{\mathrm{s}} F-2,08 \times 10^{-5} d_{\mathrm{s}} n_{\mathrm{w}}
\end{aligned} .
$$

The impact of cutting conditions on power $P_{\mathrm{c}}$ according to the created theoretical-experimental model in coded form is graphically presented in Fig. 2a. To study the surface determined by regression equations in the area of the experiment at the same level as the output parameter, two-dimensional sections have been plotted (Figs. 2b and 2c).

On the basis of the created model of cutting power (3b) and relationship (1), a theoretical-experimental model of tangential cutting force $F_{\mathrm{c}}$ has been built, depicting the complex impact of elastic abrasive cutting conditions:

$$
F_{\mathrm{c}}=\frac{1}{d_{\mathrm{s}}}\left(\begin{array}{l}
90,023+0,764 d_{\mathrm{s}}-2,591 F-0,492 n_{\mathrm{w}}+ \\
+0,134 d_{\mathrm{s}} F-0,004 d_{\mathrm{s}} n_{\mathrm{w}}
\end{array}\right) .
$$




\subsubsection{Analysis of experimental results}

The analysis of the experimental results obtained shows that:

- with the rise in workpiece rotational frequency within the studied range, the tangential force and cutting power decrease by $22 \div 25 \%$;

- the increase in the force compressing the cut-off wheel to the workpiece in the range of $1 \mathrm{daN}$ up to $3 \mathrm{daN}$ leads to an increase in the tangential force and cutting power by $15 \div 20 \%$;

- the cut-off wheel diameter has an effect (different by character) on the tangential force and cutting power: when $d_{\mathrm{s}}$ decreases, force $F_{\mathrm{c}}$ increases, and cutting power $P_{\mathrm{c}}$ decreases;

- the relation $K_{\mathrm{F}}$ between tangential force $F_{\mathrm{c}}$ and normal cutting force $F_{\mathrm{p}}\left(F_{\mathrm{p}}=F\right)$ as a parameter characterizing the cutting process effectiveness and material workability is within the range of $1,46 \div 0,39$ and depends on workpiece rotational frequency $n_{\mathrm{w}}$ and cut-off wheel diameter - $K_{\mathrm{F}}$ decreases when $n_{\mathrm{w}}$ increases and cutoff wheel diameter $d_{\mathrm{s}}$ decreases.

In order to explain the character of impact of elastic abrasive cutting conditions on the tangential force, cutting power and coefficient $K_{\mathrm{F}}=K_{\mathrm{c}} / K_{\mathrm{p}}$, the relationship between power $P_{\mathrm{c}}$ and force $F_{\mathrm{c}}(1)$, has to be taken into account as well as the relationship for determining force $F_{\mathrm{c}}$ depending on the specific cutting force $k_{\mathrm{c}}[6,8]$ :

$F_{\mathrm{c}}=z_{\mathrm{e}} F_{\mathrm{c}_{\mathrm{z}}}=z_{\mathrm{e}} k_{\mathrm{c}} A_{\mathrm{z}}$,

where: $F_{\mathrm{c}_{\mathrm{z}}}$ is a force acting on one abrasive grain in daN; $A_{\mathrm{z}}$ is the area of the cross-section of the material layer being cut by one abrasive grain in $\mathrm{mm}^{2} ; z_{\mathrm{e}}$ is the number of simultaneously working abrasive grains located in the contact area of the cut-off wheel and workpiece.

To determine area $A_{\mathrm{z}}$ and the number of simultaneously working abrasive grains $z_{\mathrm{e}}$, the following relationships are applied [19]:

$$
\begin{aligned}
& A_{\mathrm{z}}=h_{\mathrm{z}} b_{\mathrm{s}}=\frac{9 \times 10^{4} d_{\mathrm{w}}^{2} t_{\mathrm{g}}^{2} b_{\mathrm{s}}}{\tau d_{\mathrm{s}} n_{\mathrm{s}}^{2} g} \sqrt{\frac{d_{\mathrm{s}}+d_{\mathrm{w}}}{d_{\mathrm{s}} d_{\mathrm{w}} a}}, \\
& z_{\mathrm{e}}=\frac{L b_{\mathrm{s}} g}{100 t_{\mathrm{g}}^{2}},
\end{aligned}
$$

where: $\tau$ is time per cut in seconds - it is determined in accordance with the theoretical-experimental model built in [16] which reflects the complex impact of the cut-off wheel diameter, the force compressing the cut-off wheel to the workpiece and the workpiece rotational frequency:

$$
\tau=13,8064-0,0178 d_{\mathrm{s}}-F+0,0142 n_{\mathrm{w}},
$$

$a=0,5 d_{\mathrm{w}}\left(1-\sqrt{1-\frac{60}{\tau n_{\mathrm{w}}}}\right)$ is the cutting depth in $\mathrm{mm}$, $L=\sqrt{\frac{d_{\mathrm{s}} d_{\mathrm{w}} a}{d_{\mathrm{s}}+d_{\mathrm{w}}}}$ is the contact arc length in $\mathrm{mm}, b_{\mathrm{s}}$ is the width of the cut-off wheel in $\mathrm{mm}, \mathrm{g}=10 \div 12 \%$ is the relative portion of abrasive grains placed at spacing $t_{\mathrm{g}}$, actually taking part in the cutting process.
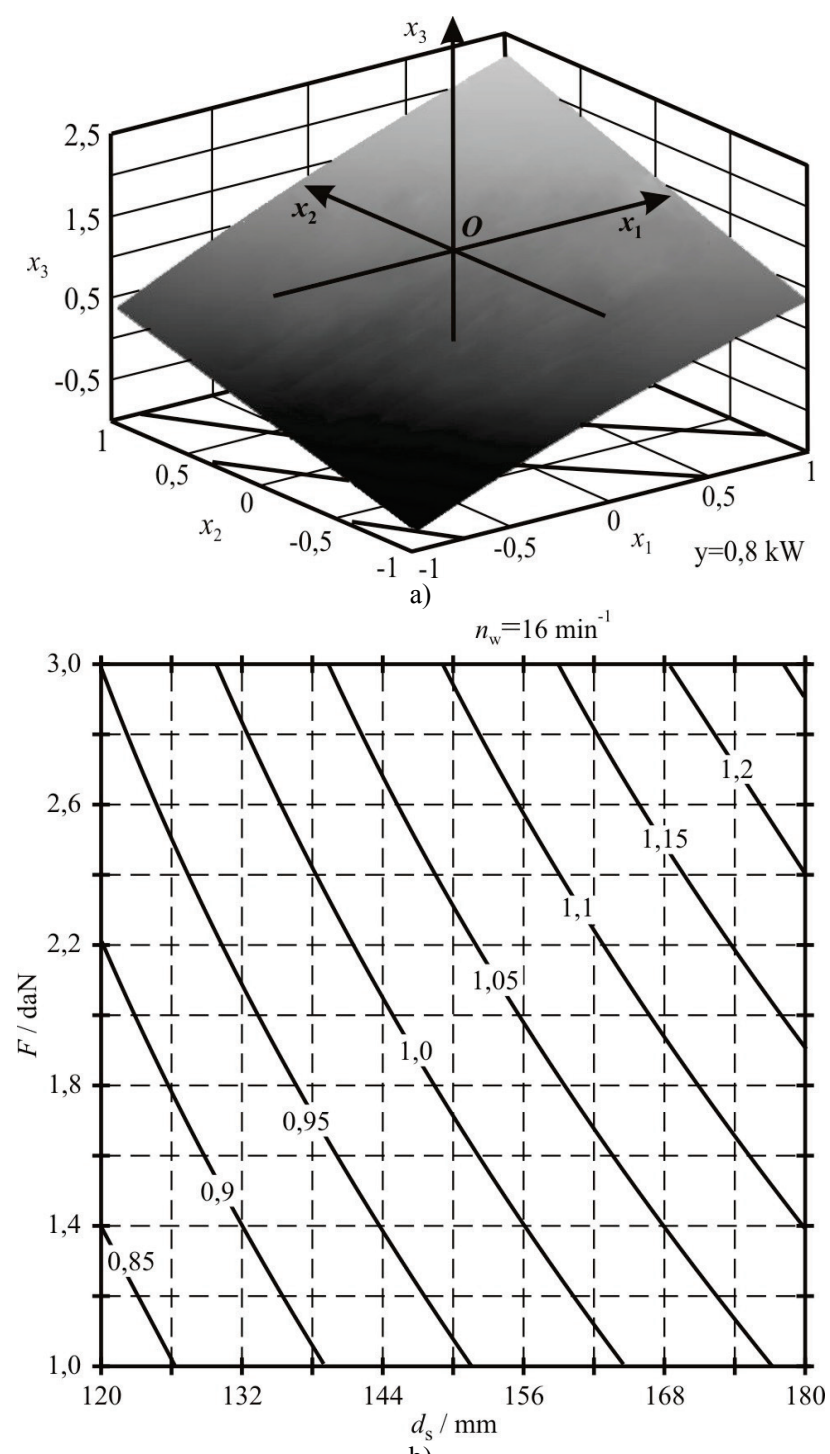

b)

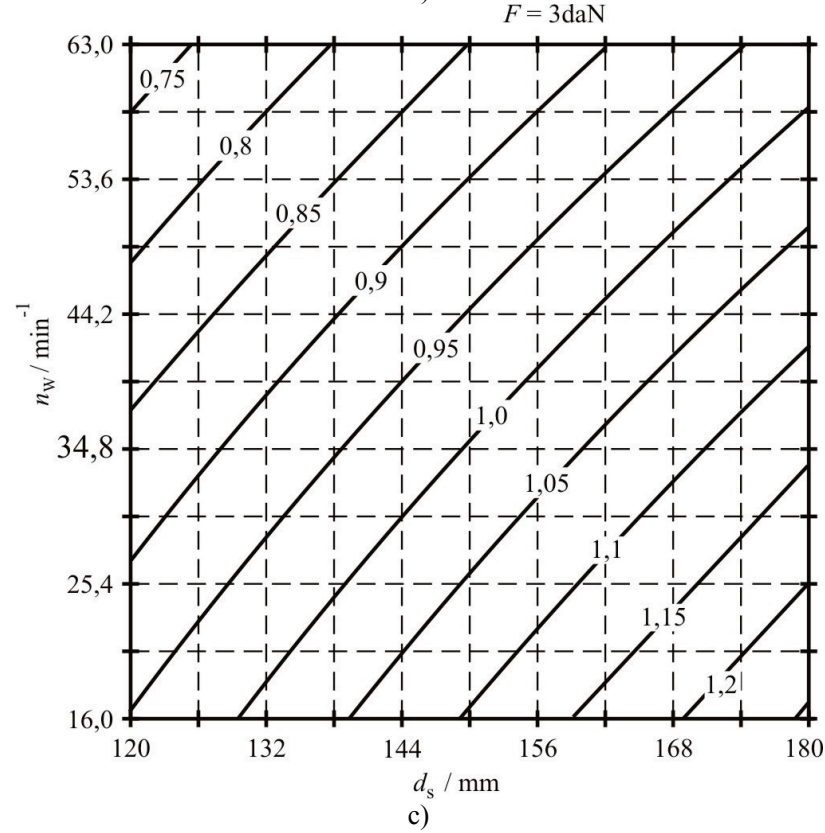

Figure 2 Impact of elastic abrasive cutting conditions on cutting power $P_{\mathrm{c}} / \mathrm{kW}$ 
The spacing between the abrasive grains is determined on the basis of an analysis of the cut-off wheel structure, taking into account the abrasive grain size $d_{\mathrm{g}}$ and the percentage content $K_{\mathrm{g}}$ of abrasive grains in the cut-off wheel volume [1]:

$t_{\mathrm{g}} \approx 180 \frac{d_{\mathrm{g}}}{K_{\mathrm{g}}}$

Specific cutting force $k_{\mathrm{c}}$ has a complicated character of variation but it always depends on the thickness of material $h_{\mathrm{z}}$ cut by one abrasive grain and the grain geometry. During elastic abrasive cutting $h_{\mathrm{z}}$ is determined by [19]:

$h_{\mathrm{z}}=\frac{47,1239 \cdot d_{\mathrm{w}}^{2}}{\tau n_{\mathrm{s}} z_{\mathrm{f}}} \sqrt{\frac{d_{\mathrm{s}}+d_{\mathrm{w}}}{d_{\mathrm{s}} d_{\mathrm{w}} a}}, \mathrm{~mm}$,

where: $z_{\mathrm{f}}=\frac{\pi d_{\mathrm{s}} g}{100 t_{\mathrm{g}}}$ is the number of abrasive grains actually participating in cutting.

The determined values of dynamic parameters (tangential force $F_{\mathrm{c}}$, cutting power $P_{\mathrm{c}}$ and specific cutting force $k_{\mathrm{c}}$ ), physical parameters (thickness $h_{\mathrm{z}}$ and area $A_{\mathrm{z}}$ of the material cut by one abrasive grain) and manufacturing parameters (cutting depth $a$ and the number of abrasive grains $z_{\mathrm{e}}$ working simultaneously) of the elastic abrasive cutting process for specified cutting conditions (Tab. 1) are presented in Tab. 2.

The analysis of relationships $(1),(5) \div(10)$, as well as of the data in Tab. 2, allows the following conclusions to be drawn:

- With the rise in workpiece rotational frequency, the specific cutting force, the number of abrasive grains working simultaneously and cutting depth decrease but the area and the thickness of the layer cut by one abrasive grain increase. As a result the decrease in tangential force and cutting power with an increase in $n_{\mathrm{w}}$ is minimum.

- With a reduction in cut-off wheel diameter, the specific cutting force, the number of abrasive grains working simultaneously and cutting depth decrease but the area and thickness of the material layer being cut by one abrasive grain increase. As a result the tangential cutting force increases insignificantly. At the same time, reduction in $d_{\mathrm{s}}$ at constant rotational frequency of the cutoff wheel $\left(n_{\mathrm{s}}=8500 \mathrm{~min}^{-1}\right)$ leads to a decrease in cutting speed $V_{\mathrm{s}}$, and as a result to cutting power as well.

- When the force compressing the cut-off wheel to the workpiece increases, the specific cutting force, the number of abrasive grains working simultaneously, cutting depth, the area and thickness of the layer being cut by one abrasive grain increase. This leads to an increase in both the tangential force and cutting power.

\subsection{Modelling of specific cutting force, tangential force and cutting power}

Specific cutting force $k_{\mathrm{c}}$ for the concrete elastic abrasive cutting conditions is within $14750 \div$ $22250 \mathrm{daN} / \mathrm{mm}^{2}$ (Tab. 2). The analysis of data from Tab. 2 shows that the force magnitude depends mainly on the thickness of the material layer being cut $h_{\mathrm{z}}$, which, on its part, is determined by workpiece rotational frequency, the force compressing the cut-off wheel to the workpiece and wheel diameter.

On the basis of the plotted curve $k_{\mathrm{c}}=f\left(h_{\mathrm{z}}\right)$ (Fig. 3) it can be assumed that the model describing the correlation between the specific cutting force and the thickness of the material layer being cut, is:

$k_{\mathrm{c}}=C_{\mathrm{k}_{\mathrm{c}}} h_{\mathrm{z}}^{-\mathrm{X}_{\mathrm{k}_{\mathrm{c}}}}$.

Table 2 Conditions and parameters of the elastic abrasive cutting process

\begin{tabular}{|c|c|c|c|c|c|c|c|c|c|c|}
\hline \multirow{2}{*}{ No } & \multicolumn{3}{|c|}{ Elastic abrasive cutting conditions } & \multicolumn{3}{c|}{$\begin{array}{c}\text { Physical and manufacturing parameters of } \\
\text { elastic abrasive cutting }\end{array}$} & \multicolumn{4}{c|}{$\begin{array}{c}\text { Dynamic parameters of elastic abrasive } \\
\text { cutting }\end{array}$} \\
\cline { 2 - 12 } & $d_{\mathrm{s}} / \mathrm{mm}$ & $F / \mathrm{daN}$ & $n_{\mathrm{w}} / \mathrm{min}^{-1}$ & $z_{\mathrm{e}}$ & $a / \mathrm{mm}$ & $h_{\mathrm{z}} / \mathrm{mm}$ & $A_{\mathrm{z}} / \mathrm{mm}^{2}$ & $P_{\mathrm{c}} / \mathrm{kW}$ & $F_{\mathrm{c}} / \mathrm{daN}$ & $k_{\mathrm{c}} / \mathrm{daN}^{2} \mathrm{~mm}^{2}$ \\
\hline 1 & 180 & 3 & 63 & 17 & 0,865 & $5,55 \times 10^{-4}$ & $3,81 \times 10^{-6}$ & 0,974 & 1,16 & 17585 \\
\hline 2 & 120 & 3 & 63 & 16 & 0,745 & $8,83 \times 10^{-4}$ & $5,52 \times 10^{-6}$ & 0,705 & 1,29 & 14750 \\
\hline 3 & 180 & 1 & 63 & 15 & 0,694 & $5,21 \times 10^{-4}$ & $3,45 \times 10^{-6}$ & 0,794 & 0,94 & 17690 \\
\hline 4 & 120 & 1 & 63 & 14 & 0,616 & $7,82 \times 10^{-4}$ & $5,04 \times 10^{-6}$ & 0,609 & 1,12 & 15920 \\
\hline 5 & 180 & 3 & 16 & 38 & 4,17 & $2,74 \times 10^{-4}$ & $1,88 \times 10^{-6}$ & 1,259 & 1,52 & 21520 \\
\hline 6 & 120 & 3 & 16 & 33 & 3,47 & $4,39 \times 10^{-4}$ & $2,74 \times 10^{-6}$ & 0,954 & 1,73 & 18920 \\
\hline 7 & 180 & 1 & 16 & 33 & 3,21 & $2,58 \times 10^{-4}$ & $1,71 \times 10^{-6}$ & 1,061 & 1,25 & 22250 \\
\hline 8 & 120 & 1 & 16 & 30 & 2,78 & $3,90 \times 10^{-4}$ & $2,52 \times 10^{-6}$ & 0,822 & 1,46 & 19380 \\
\hline
\end{tabular}

By employing the least-squares method, constant $C_{\mathrm{k}_{\mathrm{c}}}$ and exponent $X_{\mathrm{k}_{\mathrm{c}}}$ have been determined and as a result model (11) takes the form:

$$
k_{\mathrm{c}}=1662,3 h_{\mathrm{z}}^{-0,3128} .
$$

Generalizing relationships (1), (5), (6), (7), (10) and (11a), after certain transformations, for tangential cutting force $F_{\mathrm{c}}$, acting on the cut-off wheel and for cutting power $P_{\mathrm{c}}$ the following relationships are obtained:

$$
F_{\mathrm{c}}=\frac{0,353 d_{\mathrm{w}}^{1,68} g^{1,32} b_{\mathrm{s}}\left[\left(\tau n_{\mathrm{w}}\right)^{0,5}-\left(\tau n_{\mathrm{w}}-60\right)^{0,5}\right]^{0,16}}{d_{\mathrm{s}}^{0,52} t_{\mathrm{g}}^{2,32} \tau^{0,76} n_{\mathrm{w}}^{0,08} n_{\mathrm{s}}^{0,68}\left(d_{\mathrm{s}}+d_{\mathrm{w}}\right)^{0,16}}
$$

$$
P_{\mathrm{c}}=1,93 \cdot 10^{-7} \frac{d_{\mathrm{w}}^{1,68} d_{\mathrm{s}}^{0,48} n_{s}^{0,32} g^{1,32} b_{\mathrm{s}}\left(\tau n_{\mathrm{w}}-60\right)^{0,08}}{\tau^{0,76} n_{\mathrm{w}}^{0,08} t_{\mathrm{g}}^{0,68}\left(d_{\mathrm{s}}+d_{\mathrm{w}}\right)^{0,16}} .
$$

After analysis of the data in Tab. 2, taking into account cutting speed relationship $V_{\mathrm{s}}=\frac{10^{-3} \pi d_{\mathrm{s}} n_{\mathrm{s}}}{60}$, for 
these concrete elastic abrasive cutting conditions, by the least-squares method, the following relationship has been obtained for determining the power of the principal cutting motion $P_{\mathrm{c}}$ depending on speed $V_{\mathrm{s}}$ of the cut-off wheel and workpiece rotational frequency $n_{\mathrm{w}}$ :

$$
P_{\mathrm{c}}=0,141 V_{\mathrm{s}}^{0,65} n_{\mathrm{w}}^{-0,234} \text {. }
$$

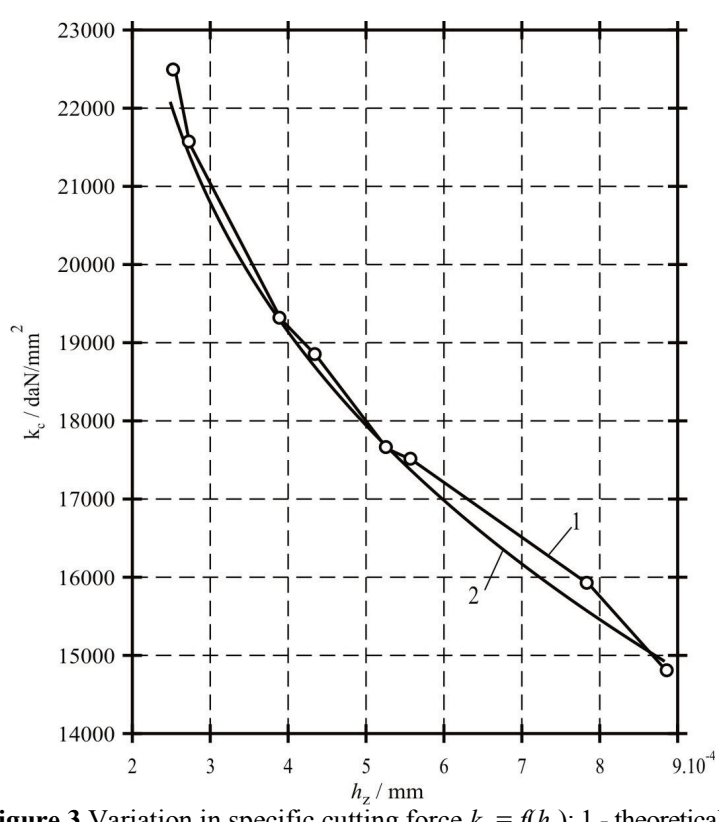

Figure 3 Variation in specific cutting force $k_{\mathrm{c}}=f\left(h_{\mathrm{z}}\right): 1$ - theoreticalexperimental; 2 - analytical

\section{Conclusion}

The complex impact of elastic abrasive cutting conditions (the force compressing the cut-off wheel to the workpiece, workpiece rotational frequency and wheel diameter) on tangential force and cutting power during elastic abrasive cutting of workpieces of C45 steel with A30RBF cut-off wheels has been studied and respective adequate theoretical-experimental models have been built.

The impact of elastic abrasive cutting conditions on tangential force and cutting power has been analyzed. This impact is related to variations in: specific cutting force, the number of abrasive grains working simultaneously, cutting depth, the area and thickness of the layer being cut by one abrasive grain depending on the force compressing the cut-off wheel to the workpiece, workpiece rotational frequency and tool diameter .

The relationship $K_{\mathrm{F}}$ between tangential and normal forces depending on elastic abrasive cutting conditions has been determined. By its variation, the serviceability of the cut-off wheel as well as the efficiency of the cutting process can be assessed.

A model of the specific cutting force has been created which proves the definite impact of the thickness of material layer cut by one abrasive grain on $k_{\mathrm{c}}$. On the basis of this model relationships have been derived for determining tangential force and cutting power depending on the cut-off wheel size and characteristic, workpiece diameter, workpiece rotational frequency and time per cut. A model for determining cutting power depending on cut-off wheel speed and workpiece rotational frequency has been obtained.

\section{References}

[1] Ganev, G. Elastic abrasive cutting of rotational workpieces in mechanical engineering. // PhD thesis, Gabrovo, 2013. (in Bulgarian)

[2] Nenkov, N.; Aleksandrova, I.; Ganev, G. Methods of abrasive cutting of workpieces. // Mashinostroene. 5-6, (1999), pp. 38-40. (in Bulgarian)

[3] Kaczmarek, K. The effect of abrasive cutting on the temperature of grinding wheel and its relative efficiency. // Archives of Civil and Mechanical Engineering. 8, 2(2008), pp. 81-91. DOI: 10.1016/S1644-9665(12)60195-2

[4] Kaczmarek, K. Using a thermovision method for measuring temperatures of a workpiece during abrasive cut-off operation. // Advance in Manufacturing science and Technology. 35, 4(2011), pp. 85-95.

[5] Nagasaka, K.; Yoshida, T.; Kita, Y.; Hashimoto, F. Optimum combination of operating parameters in abrasive cut-off. // Machine Tool \& Manufacture. 27, 2(1987), pp. 167-179. DOI: 10.1016/S0890-6955(87)80048-2

[6] Aleksandrova, I. Finishing technologies. University publishing house Vasil Aprilov, Gabrovo, 2013. (in Bulgarian)

[7] Reznikov, A. N. Abrasive and diamond machining of materials. Reference book. Mashinostroenie, Moscow, 1977. (in Russian)

[8] Stoev, Zh.; Popov, K.; Todorov, N. Abrasive machining of metals. Tehnika, Sofia, 1979. (in Bulgarian)

[9] Rowe, W. B. Principles of Modern Grinding Technology. Elsevier Inc., Oxford, 2009

[10] Kalpakjian, S. Manufacturing Process for Engineering Materials, Addison-Wesley, Menlo Park, CA, 1997.

[11] Nguwen, T.; Zhang, L. C. Performance of new segmented grinding wheel system. // International Journal of Machine Tools and Manufacture. 49, 3-4(2009), pp. 291-296. DOI: 10.1016/j.jimachtools.2008.10.015

[12] Boothroyd, G.; Winston, A.K. Fundamentals of Machining and Machine Tools. Marcel Dekker Inc., New York, 1989.

[13] Mishra, V. K.; Salonitis, K. Empirical estimation of grinding specific forces and energy based on a modified Werner grinding model. // Procedia CIRP. 8 (2013), pp. 287-292. DOI: 10.1016/j.procir.2013.06.104

[14] Neslušan, M.; Mrkvica, I.; Čep, R.; Raos, P. Heat distribution when nickel alloy grinding. // Tehnički vjesnik/Technical Gazette. 19, 4(2012), pp. 947-951.

[15] Ganev, G.; Aleksandrova, I.; Hristov, H. Wear and lifetime of abrasive tools during elastic abrasive cutting. // Machine Building and Electrical Engineering. 10-11(2012), pp. 2025. (in Bulgarian)

[16] Ganev, G.; Aleksandrova, I.; Hristov, H. Study and modelling of time for elastic abrasive cutting of rotating workpieces. // Machine Building and Electrical Engineering. 12(2012), pp. 26-31. (in Bulgarian)

[17] Chandrasekaran, M.; Devarasiddappa, D. Artificial neural network modeling for surface roughness prediction in cylindrical grinding of $\mathrm{Al}-\mathrm{SiCp}$ metal matrix composites and ANOVA analysis. // Advances in Production Engineering \& Management. 9, 2(2014), pp. 59-70. DOl: 10.14743/apem2014.2.176.

[18] Aleksandrov, A.; Aleksandrova, I. Theory of experiment. Ex-Press, Gabrovo, 2012. (in Bulgarian)

[19] Aleksandrova, I.; Hristov, H.; Ganev, G. Dynamic and Technological Characteristics of the Process Elastic Abrasive Cutting of Rotating Workpieces. // Journal of the Technical University Sofia, Branch Plovdiv. 16(2011), pp. 123-128. 


\section{Authors' addresses}

Irina Aleksandrova, Assoc. Prof., PhD

Technical University of Gabrovo, Department of Mechanical

Engineering Equipment and Technologies,

4 H. Dimirar St, Gabrovo 5300, Republic of Bulgaria

E-mail: irina@tugab.bg

\section{Gancho Ganev, PhD}

Ideal Standard - Vidima,

53 M. Popov St, Sevlievo 5400, Republic of Bulgaria

E-mail: ganevg1971@abv.bg

Hristo Hristov, Assoc. Prof., PhD

Technical University of Gabrovo, Department of Mechanical

Engineering Equipment and Technologies,

4 H. Dimirar St, Gabrovo 5300, Republic of Bulgaria

E-mail: cristof@tugab.bg 